\title{
ESTRATIGRAFIA E ORIGEM DO GRUPO BARREIRAS EM PERNAMBUCO, PARAIBA E RIO GRANDE DO NORTE*
}

\author{
J. M. MABESOONE**, A. CAMPOS E SILVA*** e K. BEURLEN****
}

\begin{abstract}
In the coastal region and some parts of the interior of Brazil, betwcen the Amazon area and Rio de Janeiro, there occurs a non-fossiliferous sedimentary sequence of Cenozoic age, called Barreiras Group. Recently, its stratigraphy has been revised and its origin determined.

Three formations can be distinguished: (1) Serra do Martins Formation of Early Tertiary age, (2) Guararapes Formation of Pliocene age, and (3) Macaiba Formation of Early Quaternary age, separated by unconformities. Every formation has its typical soil profile.

As was generally assumed, the depositional environment should have been sand and mud flows, under semi-arid climatic conditions, as correlate sediments of the relief.

Recent studies showed, however, another pattern which may lead to different interpretations.

The Serra do Martins Formation, which covered almost entirely the areas of the States of Rio Grande do Norte and Paraíba, and parts of Pernambuco, is a deposit of fluvial origin on a plain relief, not necessarily being a pediplain. Lithologically it shows kaolins, quartzites and iron-cemented sandstones. After deposition the formation suffered a strong laterization resulting in crusts of ironsandstones. Due to later monoclinal uparching, the greater part of the deposits were removed, remaining only small patches on top of tablemounts.

The Guararapes Formation, most frequent and due to its colour most conspicuous, shows really a deposition in a semi-arid environment with sand and mud flows. Some river influence can also be detected. In a few outcrops flow structures are frequent. The whole sequence is related to the formation of the relief of the region (lower pediplain). On top occurs a weathering profile (Riacho Morno) with leaching and deposition of iron oxides at a lower level or in vertical columns.

The upper Macaiba Formation is composed of a white-coloured sand to clayey sand, with a high kaolin content. The depositional environment was again fluvial, especially in fault troughs. The occurrence is therefore restricted. Its soil is a cover of yellowish to reddish fine sandy material (Potengi).

The determination of the depositional environments was made by field observations including geomorphological analyses, grain-size and sand analyses, and mineralogical composition.
\end{abstract}

INTRODUÇÃO Há muito tempo os geólogos observaram que em toda a faixa litorânea desde o Estado do Rio de Janeiro até o Pará, e mesmo ainda entrando e continuando nas baixadas amazônicas, ocorre uma seqüência notável e contínua de sedimentos, pouco ou não-consolidados, variegados, litologicamente variando entre argilas e conglomerados, apresentando normalmente uma estratificação irregular e muito indistinta. Essa seqüência bem típica como unidade e bem delimitada dentro da coluna estratigráfica repousa ora sobre o embasamento cristalino, ora sobre as formações cretáceas, ora sobre as formações terciárias marinhas, destacada da lapa por uma discordância de erosão bem pronunciada.

\footnotetext{
*'Trabalho realizado com auxílio do Conselho Nacional de Pesquisas

**Curso de Geologia, Instituto de Geociências, Universidade Federal de Pernambuco; Pesquisador-conferencista do Conselho Nacional de Pesquisas

***Departamento de Geologia, Instituto de Antropologia, Universidacle Federal do Rio Grande do Norte

****'Tübingen (Alemanha), anteriormente Curso de Geologia, Universidade Federal de Pernambuco
} 
Por outro lado, as formações quaternárias da capa - terraços fluviais, sedimentos costeiros, etc. - destacam-se tipicamente pelo fato de as mesmas não mais constituírem um capeamento extenso e contínuo, apresentando-se como formações locais, de litologia diferente.

Em geral, essa seqüuencia variegada e não-consolidada denomina-se "Barreiras". Não se trata de uma unidade litoestratigráfica (grupo, formação) nem de um nome bem definido, mesmo não existindo uma localidade típica. Porém é considerada quase sempre como uma única unidade estratigráfica por toda sua extensão na faixa litorânea; isso pode ser provável, mas, devido à própria litologia de materiais retrabalhados e redepositados, não é necessariamente verdadeiro. Faltam ainda estudos sistemáticos e detalhados das diversas representações para fins de correlação.

O termo "Barreiras", inicialmente indicando as "camadas variegadas que afloram nas diversas barreiras ao longo da costa" (Branner, 1902), assumiu gradativamente o sentido de um termo estratigráfico, sem se pensar na necessidade de uma definição ou delimitação certa ou de marcar uma localidade típica. Dessa maneira, Oliveira e Leonardos (1943) falaram em "série Barreiras", e Kegel (1957) e P. E. Oliveira e Andrade Ramos (1956) mesmo em "formação Barreiras". Daí alguns autores preferirem reunir as camadas variegad as sol, um termo neutro como, por exemplo, "Terciário superior indiviso" (Andrade, 1955) ou "Formações cenozóicas indiferenciadas" (Matoso e Robertson, 1959).

Em 1964, Bigarella e Andrade apresentaram, pela primeira vez, uma definição mais sistemática. Observaram muitas vezes, nos perfis dos arredores de Recife, uma discordância de erosão e acharam que a sequêencia inteira poderia ser subdividida em duas formações, separadas por uma desconformidade: a inferior denominada de Formação Guararapes e a superior denominada de Formação Riacho Morno. A seqüência inteira representaria, terminologicamente, um grupo: Grupo Barreiras. Mabesoone (1966) observou um comportamento análogo nas falésias do Cabo Branco (João Pessoa) e adotou a interpretação estratigráfica de Bigarella e Andrade (1964).

Campos e Silva (1965) verificou em estudos sistemáticos que, na região de Natal, aparentemente ocorre acima da Formação Riacho Morno, separada por outra desconformidade, mais uma formação superior, e denominou-a Formação Macaíba. O mesmo autor separou, finalmente, uma quarta unidade, chamada Formação Potengi, em concordância com as observações feitas por Jenkins (1913).

O Grupo de Estudos do vale do Jaguaribe (Sudene-Asmic, 1967), estudando a hidrogeologia do vale do baixo rio Jaguaribe, encontrou também dificuldades na interpretação das unidades variegadas, distinguindo duas formações: Formação Barreiras e Formação Faceira. Porém, a ambas as formações, não foi dada uma localidade típica, nem uma posição estratigráfica entre si.

No interior dos estados nordestinos, principalmente no Rio Grande do Norte, existem ainda unidades parecidas com a seqüência variegada, com variações litológicas locais, que são descritas como Séric Serra do Martins (Moraes, 1924), Infrabarreiras (Kegel, 1957), Formação Mossoró (Lins e Andrade 1960), Formação Solânea (Assis, 1967). Essas unidades não foram até agora bem definidas, possuindo, no entanto, uma certa relação entre si $e$ com o complexo das Barreiras da faixa costeira.

Neste trabalho, pretende-se dar uma redefinição do Grupo Barreiras, tanto na faixa costeira, como no interior dos Estados de Pernambuco, Paraíba e Rio Grande do Norte até o vale do baixo rio Jaguaribe, no Ceará. Trata-se de uma contribuição local, um estudo de base, para uma síntese futura do problema geológico e estratigráfico dessas sequeiencias variegadas. 
Discussão das unidades propostas GUARARAPES - RIACHO MORNO O importante trabalho de Bigarella e Andrade (1964) pelo qual foi estabelecida a subdivisão do Grupo Barreiras nas duas Formações, Guararapes e Riacho Morno, iniciou uma fase de estudos mais intensivos sobre a seqüência. Os autores correlacionaram as duas unidades com o desenvolvimento dos pediplanos da região, sendo do superior $\operatorname{Pd}_{2}$, o sedimento correlativo à Formação Guararapes, e do inferior $\mathbf{P d}_{1}$, a Formação Riacho Morno. A Formação Guararapes encontra-se principalmente nos vales dos rios atuais, enquanto a Formação Riacho Morno cobre maior extensão até nos topos dos tabuleiros.

Existem, porém, algumas evidências que colocam em dúvida essa subdivisão. Em primeiro lugar, sedimentologicamente as duas formações não podem ser distinguidas, indicando assim um mesmo ambiente de deposição (Mabesoone, 1966, 1967). Em segundo lugar, no afloramento, a Formação Guararapes é caracterizada por uma estratificação horizontal ou lenticular que coincide com a coloração das camadas. A Formação Riacho Morno não mostra tal estratificação, possuindo manchas vermelhas em forma de infiltraçōes de óxidos de ferro. A superficie inferior dessa unidade parece ser uma discordância de erosão. Além disso, há numerosas dessas discordâncias através de ambas as formações, o que corresponde bem ao ambiente de deposição continental.

O estudo pormenorizado das extensas falésias entre Cabo Branco e Barra do Gramame, na Paraíba, mostrou que a unidade Riacho Morno acompanha a superfície, parecendo assim simplesmente uma capa de intemperismo intenso, até $6 \mathrm{~m}$, da formação subjacente, isto é, Guararapes. O reexame dos numerosos afloramentos em outros lugares da faixa costeira entre Recife e a parte ocidental do Rio Grande do Norte confirmou essas observações.

Assim, as duas "Formações", Guararapes e Riacho Morno, no sentido de Bigarella e Andrade (1964), não podem ser mantidas como formações autônomas e unidades estratigráficas. A "Formação" Riacho Morno difere da "Formação" Guararapes somente por caracteres secundários, levando à conclusão de que a "Formação" Riacho Morno é uma capa de intemperismo da subjacente "Formação" Guararapes.

BARREIRAS - FAGEIRA Na publicação do Grupo de Estudos do vale do Jaguaribe (Sudene-Asmic, 1967), essas duas formações mostram as seguintes características: A "Formação" Barreiras possui uns 6 horizontes, com areias, argilas, lentes de seixos, bem friáveis, de coloração variada, com concreções ferruginosas, geralmente bem estratificados. A "Formação" Faceira inclui, além da areia branca da superficie, uma seqüência de arenitos e conglomerados de coloração clara, sem estratificação nítida e com variações bruscas de fácies. Essa última formação cobre as áreas planas mais elevadas, enquanto a "Formação" Barreiras ocorre como falésias ao longo da costa e como encostas do vale do rio Jaguaribe. Devido a esse comportamento foi concluída uma contemporaneidade das duas "formaçôes". Uma localidade típica para elas, porém, não foi dada.

MACAÍBA - POTENGI A "Formação" Macaíba foi estabelecida por Campos e Silva (1965) como uma seqüência de areias argilosas e argilas arenosas com acumulação de seixos na base, de coloração clara, que repousa sobre a unidade subjacente por uma desconformidade bem pronunciada. A localidade típica encontra-se na estrada que liga Natal a Macaíba (Rio Grande do Norte).

A "Formação" Potengi, proposta pelo mesmó autor, constitui-se de areias argilosas mal selecionadas, de coloração avermelhada, amarelada ou creme.

Ambas as unidades já foram mencionadas por Jenkins (1913), como arenito branco friável, arenito e conglomerado brancos friáveis (= Macaíba), e como arenitos vermelhos ( Potengi). 
No campo, principalmente na região de Natal, a unidade denominada Formação Macaíba é muito freqüente. Distingue-se bem das seqüências variegadas da chamada Barreiras. A unidade Potengi, porém, parece ser uma capa de intemperismo ferruginoso que se estende sobre grandes áreas na zona costeira e mesmo no interior dos três estados nordestinos aqui considerados.

SERRA DO MARTINS - INFRABARREIRAS Capeando as chapadas interioranas, ocorre uma sequêencia de arenitos caulínicos, às vezes quartzíticos, tendo na capa outro arenito, conglomerático, com cimento ferruginoso. Moraes (1924) determinou essa seqüência na Serra do Martins (RN), denominando-a Série Serra do Martins, posteriormente transformada em Formação Serra do Martins (Mabesoone, 1966). Relíquias da mesma seqüência encontram-se nos topos de várias chapadas, especialmente nos estados do Rio Grande do Norte e da Paraíba, e até mesmo no topo da serra de Mossoró (= Formação Mossoró, de Lins e Andrade, 1960).

Essa descrição corresponde perfeitamente ao conceito da "Formação Infrabarreiras", proposta por Kegel (1957). Trata-se, assim, de uma única unidade bem definida estratigraficamente.

A "Formação" Tỉbau (Campos e Silva, 1968) parece ser idêntica à Formação Serra do Martins, segundo sua litologia.

CONCLUSÃO Do acima exposto, podemos concluir os itens relacionados a seguir.

1) Existe uma unidade que corresponde à Formação Guararapes de Bigarella e Andrade (1964), capeada por um intemperismo do tipo Riacho Morno.

2) No vale do baixo rio Jaguaribe, existem duas unidades, correspondentes às Formações Barreiras e Faceira, respectivamente.

3) Existe, principalmente na região de Natal, uma unidade que corresponde à Formação Macaíba de Campos e Silva (1965), capeada por um intemperismo do tipo Potengi.

4) Nos topos das chapadas do interior, há uma seqüência arenítica, que corresponde à Formação Serra do Martins.

A correlação e definição dessas unidades é assunto que segue.

Aspecto no campo DADOS DE SUBSUPERFÍCIE Um estudo pormenorizado dos poços perfurados na região de Natal (Campos e Silva, 1969) ofereceu uma nova possibilidade para a solução do problema do Grupo Barreiras.

Segundo o referido autor, podem-se distinguir três unidades bem definidas de sedimentos continentais que repousam sobre os calcários maestrichtianos da região, conforme segue.

1) Unidade superior. Seqüência composta de areias, areias sílticas e areias argilosas, de coloração branca a avermelhada. A parte superior corresponde ao capeamento Potengi, e a parte inferior à Formação Macafba. Nessa última parte, aumenta o teor em caulim. $\mathrm{O}$ contato com a unidade subjacente é sempre uma discordância de erosão, muitas vezes marcado por cascalhos. A espessura pode atingir uns $20 \mathrm{~m}$.

2) Unidade média. Unidade predominantemente argilosa ou síltica, com cores variadas, possuindo consideráveis variações laterais. Essa seqüência parece corresponder à Formação Guararapes com capa de intemperismo Riacho Morno. A passagem para a unidade seguinte é geralmente gradativa. Sua espessura chega até $40 \mathrm{~m}$. 
3) Unidade inferior. Seqüência com predominância de areias, muitas vezes arcosianas, com uma coloração clara. Existem ainda algumas intercalações argilosas. Na parte inferior, o material mostra-se bastante silicificado. $O$ limite inferior é sempre uma desconformidade sobre os calcários cretáceos do Grupo Apodi. A espessura pode ser maior que $30 \mathrm{~m}$.

A Tab. I mostra os perfis dos dois poços mais típicos da área. Pode-se concluir que existe aqui um grupo de sedimentos, divididos em três formações bem distintas.

Foi feita, assim, uma correlação entre as áreas estudadas na superficie (Bigarella e Andrade, 1964; Sudene-Asmic, 1967; Moraes, 1924; Kegel, 1957) e a região de Natal na subsuperficie (Campos e Silva, 1969), com novos dados obtidos no campo, pelo reexame da maior. parte dos afloramentos já descritos e novos afloramentos parcialmente ou ainda não estudados.

O caráter litológico no campo, as análises sedimentológicas no laboratório, além do conhecimento geral da história geológica da região, permitem agora uma subdivisão

Tabela I - Dois perfis típicos de poços, mostrando a subdivisão do Grupo Barreiras, em Natal, (RN)

DNOCS 11-RN-67, Nova Descoberta Batalhão da Engenharia, 2.

Dunas

$0-9 \mathrm{~m}-$ areia fina

Unidade superior

$9-14-$ areia fina-grossa, branca

$14-20$ - idem, amarela

$20-21 \quad$ - areia argilosa, amarela

\section{Unidade média}

21-27 - argila compacta, vermelha

$27-28$ - idem, branca

$28-30$ - idem, vermelha-cinza

30 il - argila arenosa, vermelha

$34-37-$ scixos ferruginosos com areia argilosa vermellia

37 - 42 - argila arenosa, branca

$42-44$ - argila, castanha-clara

$44-45$ - idem, amarela

$45-51$ - areia amarela

$51-54-$ argila rósea

$54-57-$ areia amarela

57 - 58 - argila amarela

Unidade inferior

$58-65$ - areia compacta, branca

$65-68$ - argila arenosa, branca

$68-71-$ argila cinza-esbranquiçada

$71-74$ - areia branca

$74-75-$ arenito duro

$75-78$ - areia branca

$78-83-$ areia argilosa, amarela

$83-87 \quad-$ areia branca

$87-91-$ arenito duro
CASOL 102, Quintas

S/A Fiação Borborema

Dunas

$0-3 \mathrm{~m}$ - areia média

Unidade superior

$3-15$ - areia média-grossa, cinzanesbranquiçada, caulínica

$15-18$ - areia com seixos, clara

\section{Unidade média}

$18-33$ - argila síltica, vermelho-amarelada; mar rom de $30-33 \mathrm{~m}$

$33-42$ - areia fina-média, clara

\section{Unidade inferior}

$42-51$ - areia grossa, clara

51 - 54 - argila marrom-avermelhada

$54-60$ - areia média-grossa, clara

$60-66-$ argila, cinza-avermelhada

$66-90$ - areia fina-média, clara 
da sequêencia variegada, conhecida sob o nome "Barreiras", em três unidades bem distintas e estratigraficamente bem definidas. Cada unidade possui também uma capa de intemperismo típica para a mesma.

A unidade inferior, tanto na superfície como na subsuperficie, é constituída por uma seqüência arenosa até arenítica. Nas suas ocorrências nas chapadas do interior da Paraíba e do Rio Grande do Norte, possui o seguinte caráter litológico: na base, a seqüência é arenosa, friável, bastante caulínica, às vezes dificilmente distinguível da capa de intemperismo caulínico do cristalino subjacente, de coloração branca com algumas camadas mais escuras, geralmente de cores roxas e amarelas; para cima, essas areias caulínicas tornam-se arenitos, localmente silicificados até quartzitos sedimentares; na parte superior, há uma seqüência arenosa até conglomerática, com cimento ferruginoso e bastante dura. Encerra a sequiência total um capa laterítica, de arenitos ferruginosos, seja em blocos soltos, seja ainda em forma de crosta. Na direção da costa: Serra de Mossoró, horsl de Tibau, horst de Mamanguape, os sedimentos tornam-se melhor selecionados e menos duros; na subsuperfície, na região de Natal, existe uma seqüência essencialmente arenítica, que se torna $\mathrm{em}$ baixo quartzítica. Nessas regiões costeiras, a seqüência superior ferruginosa geralmente falta, talvez devido à erosão posterior. As cores são também claras. Em resumo: a unidade compõe-se de dois pacotes bastante distintos, um inferior, branco, e um superior, avermelhado.

Segue-se a chamada unidade média, que se compõe da conhecida seqüência variegada, com sedimentos arenosos até argilosos, em camadas horizontais ou em lentes, com pequenas discordâncias de erosão local, marcadas por leitos de seixos. Assim, corresponde à descrição inicial das "Barreiras", caracterizada por uma seqüência muito heterogênea, de maneira tal que não há, nem mesmo em localidades vizinhas, dois perfis iguais. No campo, os depósitos chamam a atenção pelas suas cores vivas e pela sua estratificação irregular. Essa irregularidade transforma-se, em alguns afloramentos, numa laminação perturbada. No topo, existe uma capa de intemperismo, que destruiu a estratificação original pela infiltração de óxidos de ferro. Esses óxidos de ferro apresentam-se em manchas ou colunas verticais, às vezes cimentados até arenitos ferruginosos. Essa capa segue mais ou menos a superficie atual, porém é truncada nos vales mais profundos. A unidade encontra-se ao longo da costa, constituindo as barreiras dos rios, inclusive do baixo Jaguaribe, e as falésias das praias, desde Recife até Aracati (CE).

Na capa ocorre ainda uma unidade superior, constituída por uma seqüencia essencialmente arenosa até argilosa, de coloração clara, com bastante caulim, tendo na base um horizonte de espessura variável de seixos de quartzo e rochas cristalinas. A granulação é bastante irregular e a estratificação muito indistinta. Toda a sequiência parece, assim, ser muito homogênea. Raramente ocorrem concentrações de óxidos de ferro, em forma de pequenas manchas alaranjadas até avermelhadas. A formação está separada da unidade subjacente por uma evidente discordância de erosão. Ela se encontra ao sul do Recife nos montes Guararapes, entre João Pessoa (Cabo Branco) e os topos dos tabuleiros do vale do baixo rio Jaguaribe, com sua melhor aparência na região de Natal e Macaíba, não constituindo, porém, uma ocorrência contínua. Capeia-a uma série de intemperismo, pouco espessa, de areias até siltes avermelhados. Esse capeamento pode estender-se também sobre o intemperismo da unidade média, truncando-a.

Correlação e definiçăo estratigráfica Com esses novos dados pode-se estabelecer uma coluna estratigráfica das unidades descritas para os Estados de Pernambuco, Paraíba e Rio Grande do Norte, desde o Recife até o vale do rio Jaguaribe, no Geará. 
Trata-se, aparentemente, de três formações bem distintas e de idades diferentes. A unidade inferior foi denominada de Formação serra do Martıns. Sua seção típica encontra-se na própria serra (Tab. II). Essa formação, dada sua ocorrência, cobriu anteriormente muito mais do Nordeste, constituindo mesmo uma capa contínua, desde o interior até a costa. Nessa formação estão incluídas as Formações Serra do Martins, Mossoró, Tibau e Infrabarreiras, além da unidade inferior de superfície e subsuperficie, ora descrita. Depois da sua sedimentação, sofreu de um intemperismo profundo de tipo laterítico (chamado de Intemperismo laterítico, como unidade edafoestratigráfica), indicando assim um hiato até a formação seguinte.

Tabela II - Formação Serra do Martins; Seção-tipo: Serra do Martins, Martins (RN)

6) Laterito, blocos na superficie

5) Arenito argiloso, coloração branca ou creme, diagênese média; laterizado na capa $8 \mathrm{~m}$

4) Sedimento arenoso grosseiro, de coloração roxa, com intercalações de camadas argilosas $6 \mathrm{~m}$

3) Sedimento arenoso, de coloração roxa, laminação distinta $12 \mathrm{~m}$

2) Sedimento argilo-arenoso, de coloração amarelo-avermelhada, laminação indistinta $20 \mathrm{~m}$

1) Sedimento areno-síltico, creme, mosqueamento discreto, sem estratificação $4 \mathrm{~m}$

Embasamento cristalino

Para a unidade média foi mantido o nome de Formação Guararapes. Sua seção típica está no lugar onde foi descrita por Bigarella e Andrade (1964), nos morros Guararapes no Recife. Porém a constante exploração nos referidos morros tem acabado com a localidade exata estudada pelos mencionados autores; dessa maneira, a descrição original não pôde ser mantida, principalmente devido à rápida mudança de fácies dentro da tormação. A descrição dada na Tab. III da seção-tipo da Formação Guararapes baseia-se, assim, num levantamento posterior feito pela aluna-bolsista Coutinho (1966), confirmado durante as últimas investigações efetuadas na área. Nessa unidade são incluídas as Formações Guararapes, Riacho Morno e Barreiras (do vale do Jaguaribe), além das unidades médias de superficic c subsuperficie. Depois da sua deposição, sofreu um intemperismo com certa lixiviação e concentração dos óxidos de ferro, capa esta denominada de intemperismo Riacho Morno. Desse modo, existe um hiato entre essa formação e a unidade sobrejacente.

Tabela III - Formação Guararapes; Seção-tipo: Montes Guararapes, Recife (PE)

11) Sedimento síltico-argiloso, cor roxa bem clara

10) Sedimento síltico-argiloso, cor amarelada $\quad 0,30 \mathrm{~m}$

9) Sedimento síltico-argiloso, cor vermelha $\quad 1,20 \mathrm{~m}$

8) Areia argilosa de aspecto homogêneo, seleção boa, coloração vermelho-amarelada $0,90 \mathrm{~m}$

7) Areia arcosiana, coloração amarelo-esbranquiçada $\quad 1,20 \mathrm{~m}$

6) Areia síltica, vermelha $\quad 1,40 \mathrm{~m}$

5) Areia pouco grosseira, coloração vermelho-vivo, com caulim $\quad 2,80 \mathrm{~m}$

4) Horizonte de seixos angulosos de quartzo $0,05 \mathrm{~m}$

3) Areia quartzosa-arcosiana, de coloração roxa intensa, com seixos; ocorre às vezes sob a forma de lentes; apresenta contato irregular

2) Areia amarela, com pequenos seixos de quartzo, sem caulim, sem estratificação 1,20 m

1) Arenito vermelho-grosseiro, com camadas de caulim da espessura de $0,2 \mathrm{~cm}$, conferindo um aspecto bastante estratificado 
A unidade superior ficou com o nome de Formação Macaiba. Sua seção típica encontra-se na estrada de Natal a Macaíba, a uns $6 \mathrm{~km}$ da última cidade (Tab. IV). A base não aflora na seção-tipo originalmente determinada; assim, a tabela menciona também uma seção mais completa, em outra localidade. Essa formação ocorre irregularmente na faixa costeira entre Recife e Natal, aparecendo também na região da chapada do Apodi e no vale do baixo rio Jaguaribe. Incluem-se nela, as Formações Macaiba, Potengi e Faceira, além da unidade superior de superficie e subsuperficie. Depois de sua deposição, sofru um intemperismo, com concentração de óxidos de ferro na superficie, sem constituir, contudo, crostas inteiras. Esse capeamento foi chamado de intemperismo Potengi.

Tabela IV - Formação Macaíba

Seção-tipo: Macaíba (RN) -

3) Areia argilosa, avermelhada, sem estratificação; às vezes fragmentos de quartzo e laterito na lapa (Intemperismo Potengi)

2) Areia argilosa, caulínica, branca, sem estratificação, com eventuais manchas de óxidos de ferro Base nåo-visivel

Seção mais completa: Barreira d'Água, Natal (RN)

3) Areia argilosa, creme a alaranjada, mal selecionada (Intemperismo Potengi)

2) Areia argilosa, caulínica, branca, com algumas manchas avermelhadas ou amareladas de óxidos de ferro

1) Leito de seixos de quartzo e fragmentos de rochas cristalinas ácidas - Discordância

Formação Guararapes com intemperismo Riacho Morno

Essas três formações foram juntadas como Grupo Barreiras. Suas ocorrências nos Estados de Pernambuco, Paraíba e Rio Grande do Norte são resumidas na Fig. 1. A Fig. 2 dá dois perfis típicos através da área, enquanto a Tab. VI apresenta a coluna estratigráfica do grupo.

Idade A datação estratigráfica das diversas formações afossilíferas do Grupo Barreiras e dos acontecimentos geomorfológicos e epirogenéticos relacionados é muito problemática. Tanto Bigarella e Andrade (1964), como Mabesoone (1966) dataram essas formações em bases paleoclimáticas.

Porém não existe nenhum fundamento certo de uma tal correlação. $O$ desenvolvimento paleoclimático do hemisfério Norte é relativamente bem conhecido, durante o Cenozóico da Europa e da América do Norte; mas o desenvolvimento paleoclimático do hemisfério Sul é quase desconhecido. Mesmo a correlação das fases glaciais do Quaternário entre América do Sul e América do Norte-Europa ainda é problemática. Nas zonas tropicais, os contrastes climáticos da periodicidade paleoclimática são muito reduzidos (Büdel, 1953); o desenvolvimento paleoclimático é mais homogêneo do que nas zonas de climas moderados.

O único indício certo de uma datação estratigráfica é o fato de que as camadas do equivalente da Formação Guararapes na região de Belém do Pará repousam sobre a Formação Pirabas, de idade miocênica inferior. No Rio Grande do Norte, os depósitos da mesma formação são mais recentes do que o vulcanismo basáltico do Cabugi, que, conforme datações geocronológicas, também é de idade miocênica. Dessa maneira, pode-se supor que a Formação Guararapes seja de idade miocênica superior ou pliocênica. $O$ intemperismo Riacho Morno seria do Plioceno superior, formado num período relativamente 


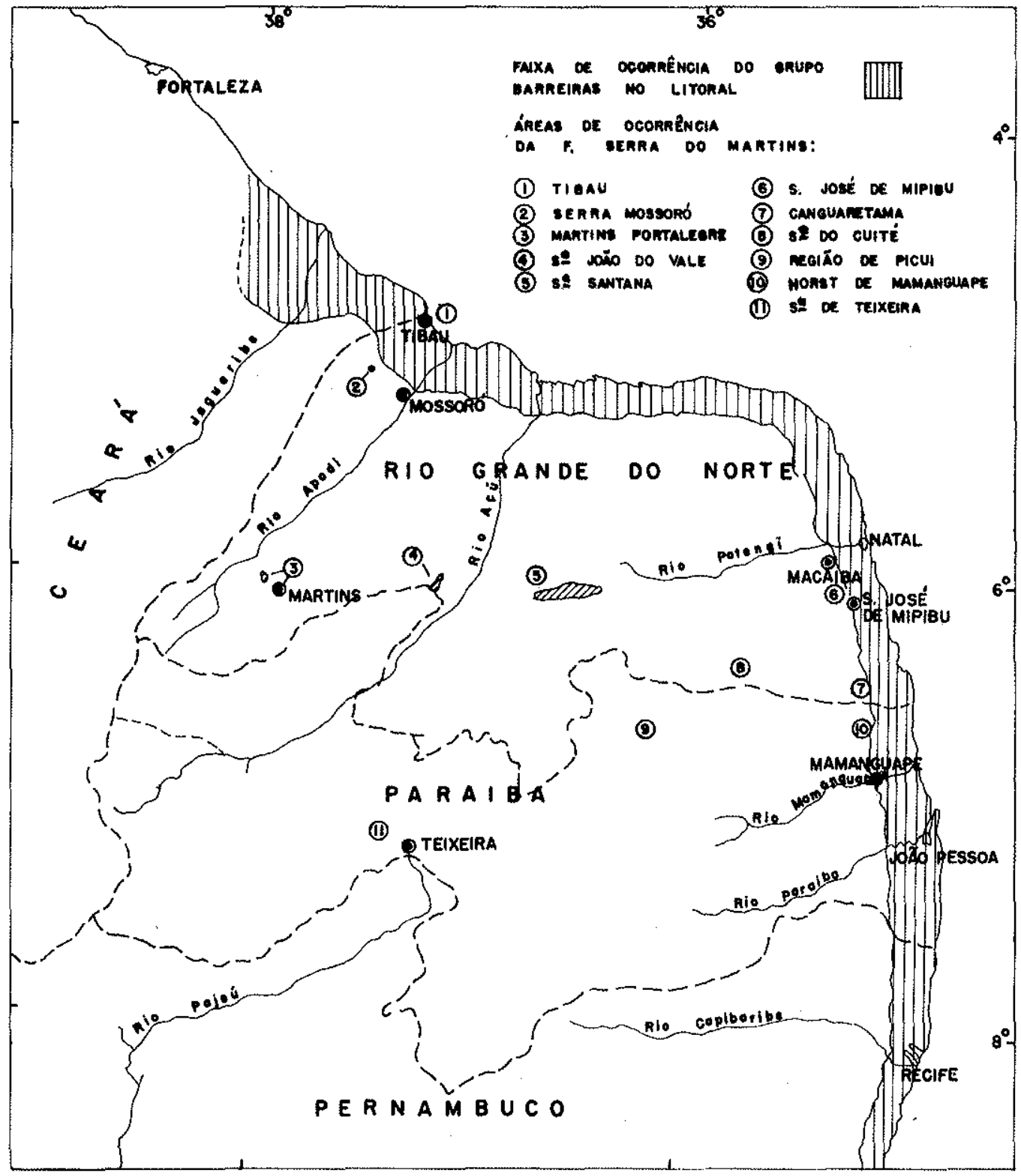

Figura 1 - Ocorrência do grupo Barreiras nos Estados de Pernambuco, Paraíba e Rio Grande do Norte

longo, considerando-se a profundidade de 5-6 $\mathrm{m}$ da capa intemperizada. No sentido do relevo, a Formação Guararapes corresponde ao pediplano mais recente $\left(\mathrm{Pd}_{1}\right.$, de Bigarella e Ab'Sáber, $1964=$ superfície de Velhas, de King, 1956); a formação é sem dúvida um depósito correlativo desse relevo.

A Formação Serra do Martins cobre os topos das chapadas e serras em altitudes correspondentes ao pediplano superior da região $\left(\mathrm{Pd}_{2}\right.$, de Bigarella e Ab'Sáber 1964 = superficie Sul-americana, de King, 1956). Dessa maneira, pode ser um depósito correlativo dessa pediplanização ou de um período um pouco posterior, como sedimento sobre uma 


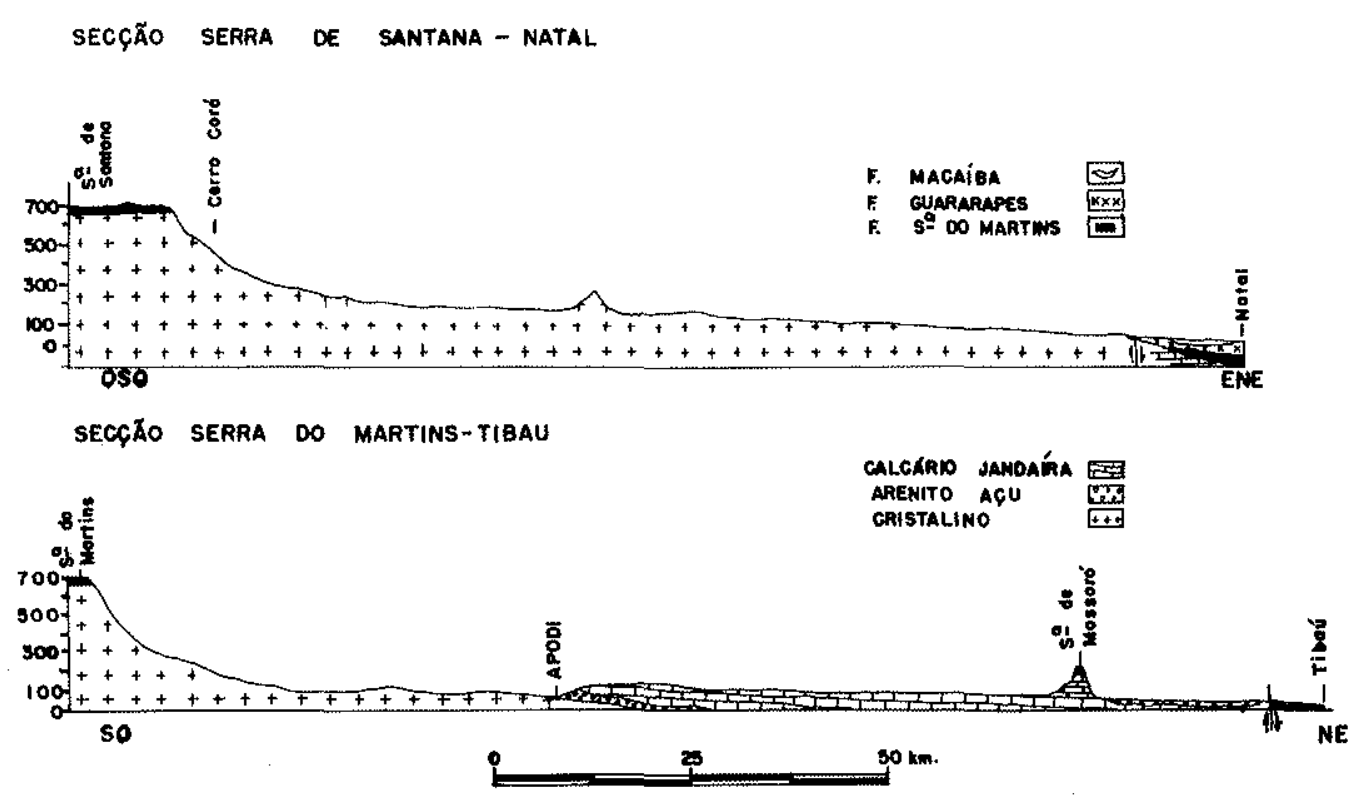

Figura 2-Dois perfis através da área com ocorrência do grupo Barreiras

planície já formada. O referido pediplano foi abaulado depois da sua formação. Segundo dados recentes, apresentados por Almeida (1969), esse movimento epirogenético aconteceu no Oligoceno superior até Mioceno inferior, acompanhado pelo vulcanismo basáltico do Rio Grande do Norte (Cabugi). Isso significaria, para a Formação Serra do Martins, uma provável idade oligocênica ou um pouco mais antiga. De qualquer maneira, sua ocorrência na faixa costeira em posição discordante sobre os calcários maestrichtianos do Grupo Apodi indica uma idade cenozóica.

Depois da fase de intemperismo Riacho Morno, começou uma nova fase de erosão, especialmente nos grabens do rio Paraíba (PB), Potengi (RN), Jaguaribe (GE) c ao sul do Recife (PE). Nas partes mais baixas, depositaram-se os sedimentos da Formação Macaiba. A época dessa sedimentação é, assim, pós-pliocênica, isto é, quaternária inferior. Finalmente, durante o Quaternário houve um novo período de intemperismo, possivelmente com alguma ressedimentação simultânea, resultando no capeamento Potengi, presente nas faixas costeiras de quase toda a área estudada. As supostas idades ficam ainda a ser confirmadas; elas são mencionadas também na Tab. VI.

Durante o Pleistoceno superior até o Holoceno, há ainda mais uma fase certa de acumulação, resultando nas areias brancas e as areias de outras cores encontradas acima dos atuais tabuleiros costeiros. Ao que parece, essa fase ainda está perdurando. Entretanto pesquisas posteriores deverão confirmar tais idéias; a fase não foi incluída, por enquanto, no Grupo Barreiras.

Ambientes de deposição A determinação dos prováveis ambientes de sedimentação foi efetuada pela ajuda da composição granulométrica e o caráter morfoscópico e morfométrico dos grãos de areia. Das amostras cimentadas fizeram-se lâminas petrográficas, estudadas ao microscópio. Os métodos utilizados foram descritos por Mabesoone (1968a, Cap. 11). 
FORMAÇÃO SERRA DO MARTINS A Fig. 3, diagrama superior, apresenta as curvas cumulativas da composição granulométrica de algumas amostras representativas da formação inferior do Grupo Barreiras; a Tab. V dá os parâmetros estatísticos.

As curvas separadas e a zona SM representam as diversas camadas da seção-tipo da formação na própria Serra do Martins. A maior parte das análises foi feita em lâminas petrográficas, calculando-se a curva segundo o método de Friedman (1958). A forma das curvas dá distribuições típicas de $\mathrm{S}$ e $\mathrm{T}$, às vezes com um pouco de material $\mathrm{R}$. Duas amostras (B, E) mostram-se mais finas, $\mathrm{T}$ com pouco $\mathrm{S}$. Segundo as curvas e os valores de seleção, trata-se de sedimentos depositados por águas correntes, principalmente no ambiente fluvial. Os grãos são subangulosos, enquanto a matriz argilosa encontra-se geralmente sem orientação na massa. Apenas em escala de afloramento pode-se distinguir uma laminação até estratificação.

O diagrama de zona $T$ representa as amostras da ocorrência na praia de Tibau (RN). As curvas são mais frações $S$, com melhor seleção, e os grãos de areia são mais arredondados.

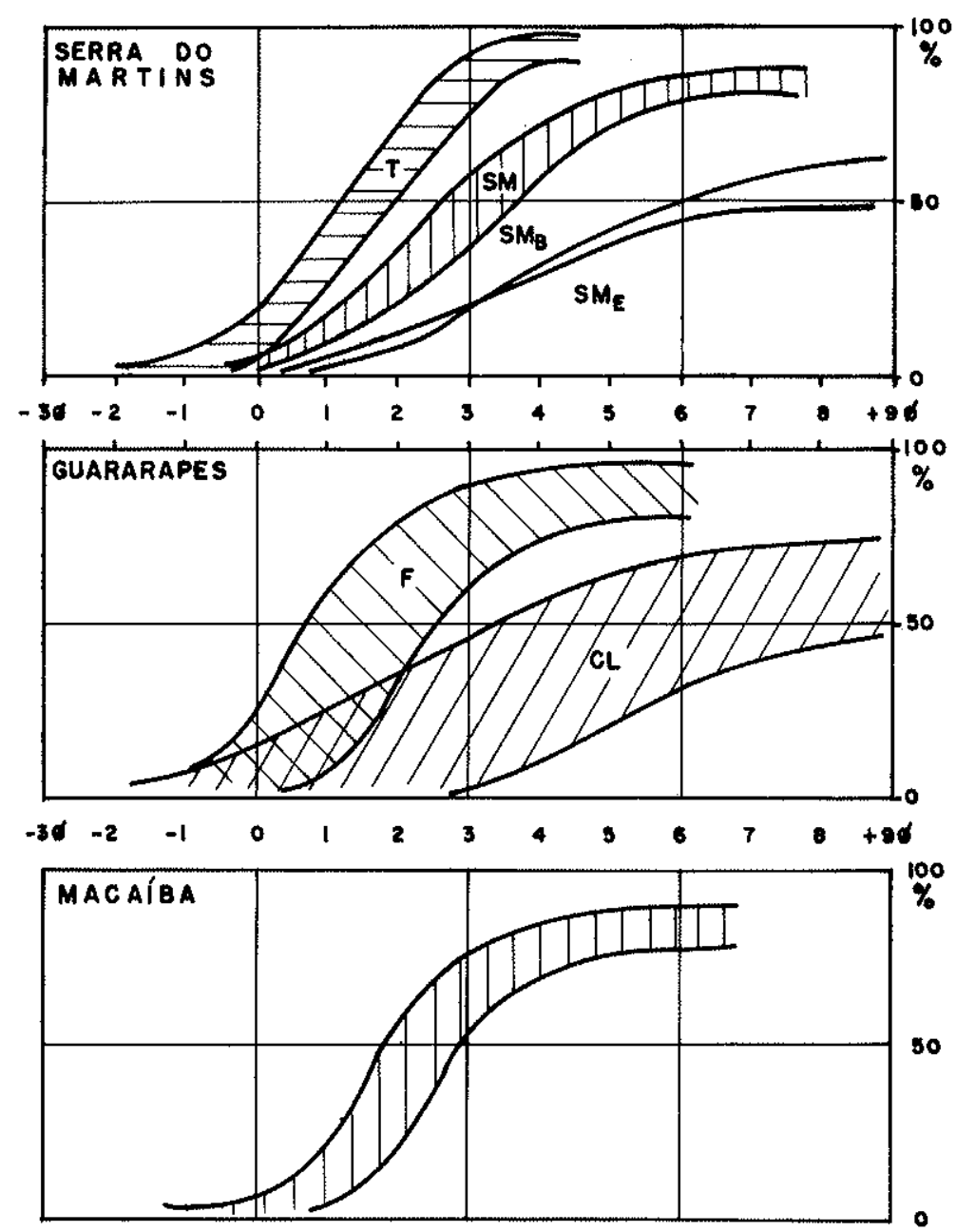

Figura 3 - Diagramas de zona de curvas cumulativas da distribuição granulométrica dos depósitos das três formações do grupo Barreiras 
Tabela V - Parâmetros estatísticos de análises gramulométricas das diversas unidades do Grupo Barreiras

\begin{tabular}{|c|c|c|c|}
\hline & $\mathrm{Md}$ & Qd & Skq \\
\hline $\begin{array}{l}\text { Formação Serra do Martins: } \\
\text { zona } \mathrm{T} \text { (Tibau, RN) } \\
\text { zona } \mathrm{SM} \text { (Serra do Martins) } \\
\text { curva } \mathrm{SM}_{\mathrm{B}} \\
\text { curva } \mathrm{SM}_{\mathrm{E}}\end{array}$ & $\begin{array}{l}1,20-2,00 \\
2,65-3,70 \\
6,00 \\
9,00\end{array}$ & $\begin{array}{l}0,30-0,50 \\
1,35-1,58 \\
\text { n.d. } \\
\text { n.d. }\end{array}$ & $\begin{array}{l}-0,05-+0,10 \\
-0,10-0,25 \\
\text { n.d. } \\
\text { n.d. }\end{array}$ \\
\hline $\begin{array}{l}\text { Formação Guararapes: } \\
\text { zona F (fluvial) } \\
\text { zona CL (corrida de lama) }\end{array}$ & $\begin{array}{c}0,70-2,50 \\
3,30=>9,00\end{array}$ & $\begin{array}{c}0,55-1,50 \\
2,00->4,00\end{array}$ & $\begin{array}{c}+0,05-+2,00 \\
\text { n.d. }\end{array}$ \\
\hline $\begin{array}{l}\text { Formação Macaíba: } \\
\text { zona }\end{array}$ & $1,80-2,90$ & $0,40-1,90$ & $+0,10-1,80$ \\
\hline n.d. nàu-determinàcel & - & & \\
\hline
\end{tabular}

O ambiente de deposição era ainda fluvial, porém a uma distância maior da fonte. Uma certa influência dos processos litorâneos não pode ser excluída.

Em geral, as amostras da Serra do Martins são as menos maduras. Na direção norte (Serra de Mossoró, horst de Tibau) e leste (Serras de Santana, Guité, horst de Mamanguape), as amostras tornam-se mais maduras, melhor selecionadas, e com grãos mais arredondados. Por exemplo: os quartzitos da Serra de Santana, comparados com os do horst de Mamanguape, são da mesma composição e diagênese, mostrando os grãos detríticos primários muito mais arredondados na ocorrência mais perto da costa.

Os estudos sedimentológicos confirmam, dessa maneira, a suposição de a Formação Serra do Martins ter coberto anteriormente uma área mais extensa na região estudada, ou mesmo ter constituído uma cobertura total da área.

FORMAÇÃO GUARARAPES Essa formação é a melhor conhecida no campo, principalmente por constituir a maior parte das falésias da costa nordestina.

A Fig. 3, diagrama médio, apresenta em duas zonas as curvas cumulativas dos seus depósitos; a Tab. V dá os parâmetros estatísticos correspondentes. Não foram mais distinguidos os quatro grupos anteriores (Mabesoone, 1967). As novas interpretações permitiram uma redução em dois grupos, cujas origens podem ser bem definidas. $O$ primeiro grupo (zona F, na Fig. 3 - médio) mostra distribuições $S$ com $T$, isto é, de origem tipicamente fluvial. $\mathrm{O}$ segundo grupo (CL) possui mais características de distribuições $\mathrm{T}$ com pequena quantidade de $\mathrm{S}$; são mais indicativas para corridas de lama e de areia (comparar Bull, 1963). Esses dois grupos manifestam-se também na morfometria e morfoscopia dos grãos de quartzo, possuindo os depósitos fluviais grãos um pouco mais arredondados.

A composição mineralógica da fração argila, como determinada por Rao e outros (1962) mostra uma quase exclusividade do mineral caulinita. O conteúdo em minerais pesados (Mabesoone, 1968b) indica apenas uma origem de fontes locais, devido a variações nas associações desses minerais.

No campo são bem notáveis várias estruturas sedimentares, especialmente pelas suas diferenças de cor. A estratificação irregular constitui, às vezes, uma estratificação perturbada, até convoluta. A Fig. 4 dá uma idéia dessas estruturas sedimentares. Interpretando e comparando-as com os exemplos dados por Coleman e Gagliano (1965), podem-se distinguir os seguintes tipos: laminação cruzada indistinta, laminação lenticular e laminação 


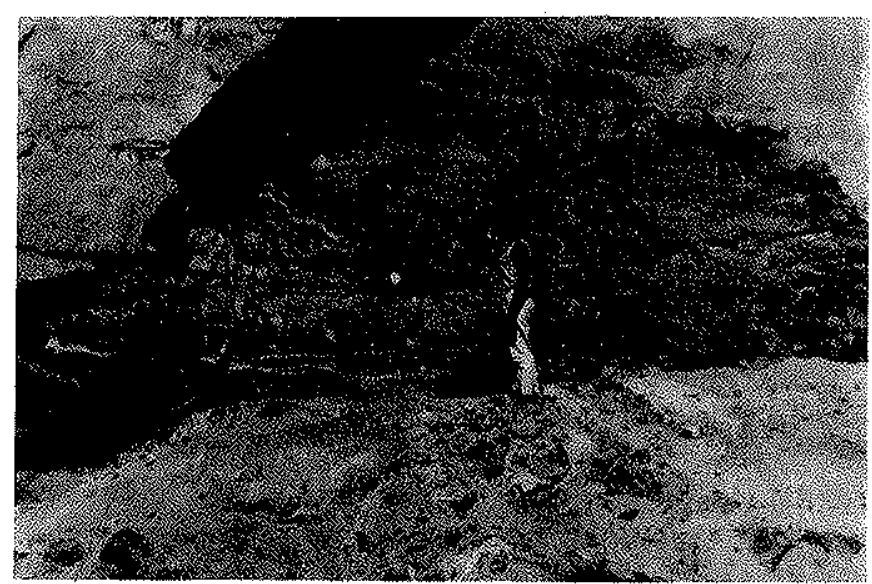

Figura 4 - Estruturas sedimentares (laminação perturbada) no afloramento dos Montes Guararapes, Recife (PE). Formação Guararapes

perturbada ou convoluta. Uma laminação cruzada indistinta indica uma tração no leito da corrente, sob condições variáveis de velocidade da corrente e carga transportada. A laminação lenticular forma-se geralmente como concentrações de areia numa massa síltico-argilosa; indica uma certa ação de ondas oscilantes sobre um fundo de lama. A laminação perturbada, com muitas concentrações e estruturas irregulares, é comum, especialmente num ambiente fluvial. Há estruturas de deslizamento em pequena escala, pequenas dobras causadas por excesso de carga em movimento lento e laminação convoluta, como conseqüência de forte correnteza e turbulência durante enchentes. Todas essas estruturas são típicas para um ambiente deltaico. $O$ fato de elas terem sido encontradas na Formação Guararapes, tão bem marcadas pelas diferenças em cor das diversas lâminas, faz pensar que o material depositou-se, quando a corrente, fluvial ou de lama, espalhou-se, em forma de leque, sobre uma planície já existente, talvez costeira. É justamente nos limites da planície do Recife, onde as estruturas descritas são tão freqüentes.

A conclusão sobre o ambiente de deposição da Formação Guararapes é, assim, uma combinação de corridas de lama e rios. Isso indica também um clima bastante rigoroso, semi-árido, na época da sedimentação. Nesse caso, a formação é um verdadeiro sedimento correlativo do relevo.

FORMAÇÃO MACAÍBA A Formação Macaíba é mais homogênea. A Fig. 3, diagrama inferior, mostra uma zona relativamente estreita, na qual se encontram quase todas as curvas cumulativas dos diversos depósitos. Assim, os parâmetros estatísticos variam também dentro de limites próximos (Tab. V).

Trata-se, na diferenciação do material sedimentar, de distribuições $\mathrm{S}$ mais $\mathrm{T}$. Os grãos de areia são subangulosos, geralmente não-desgastados. Todos esses dados sugerem, de novo, um ambiente fluvial para a sedimentação dessa formação.

A composição mostra, na fração fina, muito caulim. Isso causa o aspecto branco no campo. O caulim, como sedimento fluvial, indica um intemperismo químico bastante forte na área de origem do material. Além disso, a homogeneidade do pacote, com exceção da camada de seixos da base, sugere uma deposição bastante rápida, por correntes que se concentram em certas áreas, isto é, as depressões tectônicas pré-existentes. Existe até a possibilidade da Formação Macaiba ser consequiência dessa ação tectônica de falhamento, a qual causou o desequilíbrio necessário para o transporte do material. 
Origem das unidades Sobre a origem e procedência dos depósitos das três formações do Grupo Barreiras existem ainda algumas incertezas. Em publicações anteriores (King, 1956; Bigarella e Ab'Sáber, 1964), uma origem como material detrítico desintegrado pelos processos de clima semi-árido é admitida. Nesse caso, o meio de transporte mais provável seria a corrida de lama ou de areia. As análises sedimentológicas, porém, nào confirmam um tal transporte para os depósitos das Formações Serra do Martins e Macaíba; mesmo a Formação Guararapes possui grande número de sedimentos fluviais. Isso significa que o clima durante a deposição das Formações Serra do Martins e Macaíba não era tão seco como se pensava; possivelmente reinava um clima ainda bastante úmido. Durante a deposição da Formação Guararapes, o clima era semi-árido, confirmando observações anteriores.

Os sedimentos das três formações do Grupo Barreiras são bastante feldspáticos, geralmente transformados em caulim. Eles possuem concentrações de óxidos de ferro junto a camadas lixiviadas brancas e mostram cores variadas. Mesmo uma silicificação, como ocorre dentro da Formação Serra do Martins, estende-se sobre extensas áreas. Todas essas características são indicativas da chamada "fácies siderolítica", no sentido de Millot (1967). Essa fácies caracteriza-se pelas extremas variedades litológicas, algumas delas mencionadas acima. Todos os autores concordam na interpretação de serem esses depósitos produtos de retrabalhamento de extensas e espessas capas lateríticas tropicais. A formação do material é chamada "fase de laterização" (Fleury, 1909) ou "biostasia" (Erhart, 1956); o transporte e a redeposição representam a "fase siderolítica" ou "resistasia", respectivamente. Os solos que produziram os materiais da Formação Serra do Martins desenvolveram-se sobre rochas cristalinas, restos dos quais ainda ficaram preservados. Os solos que deram origem ao sedimento para a Formação Guararapes são as capas lateríticas ainda presentes acima da Formação Serra do Martins (o chamado intemperismo laterítico). Finalmente, os solos que produziram os sedimentos da Formação Macaíba, pertencem ao intemperismo Riacho Morno da Formação Guararapes. O retrabalhamento, a fase de resistasia, que transportou e redepositou esses materiais, foi causado seja por movimentos tectônicos seja por mudanças de clima. As implicações geomórficas dessas rupturas do equilíbrio serão tratadas num outro trabalho.

A área de origem da Formação Serra do Martins era bastante próxima à atual Serra do Martins, dada a imaturidade dos sedimentos dessa ocorrência. Com o aumento do transporte para a costa, os sedimentos tornam-se cada vez mais maduros e arredondados. Essa área de origem encontrava-se ao sul da Serra do Martins, onde atualmente existe ainda um relevo do cristalino bastante acidentado com altitudes de até $1000 \mathrm{~m}$. A drenagem transportou o material para norte (direção de Tibau), para leste (direção de Natal e Mamanguape) e, possivelmente, também para sul (direção do rio São Francisco).

A área de procedência dos sedimentos da Formação Guararapes era a capa da Formação Serra do Martins e rochas cristalinas aflorando naquela época. Da mesma maneira, originou-se o depósito da Formação Macaíba, dos sedimentos restantes das formações sedimentares mais antigas e do cristalino.

CONCLUSÃo Do acima exposto pode-se concluir que a sequêencia variegada das "Barreiras" constitui um Grupo, subdividido em três formações: Serra do Martins, Guararapes e Macaíba, respectivamente, que foram depositadas em épocas cenozóicas, como conseqüência da formação do relevo, dos movimentos tectônicos de abaulamento e falhamento, e dos diferentes paleoclimas da região (Tab. VI). A proposta subdivisão vale apenas para. os Estados de Pernambuco, Paraíba e Rio Grande do Norte, até o vale do baixo rio Jaguaribe, no extremo leste do Ceará. Sua extensão para outros estados deve ainda ser estudada. 
Tabela VI - Estratigrafia e origem do Grupo Barreiras em Pernambuco, Paraíba e Rio Grande do Norte

\begin{tabular}{|c|c|c|c|}
\hline \multirow{2}{*}{$\begin{array}{l}\text { IDADE } \\
\text { suposta }\end{array}$} & \multicolumn{2}{|r|}{ UNIDADES ESTRATIGRÁFICAS } & \multirow{2}{*}{ FASES BIOCLIMÁTICAS/TECTŌNICAS } \\
\hline & & EDAFO- & \\
\hline Holoceno & & areias brancas (?) & siderolítica (resistásica-climática) \\
\hline Pleistoceno & $\stackrel{\mathscr{a}}{\mathbb{G}}$ & $\begin{array}{l}\text { discordancia } \\
\text { intemperismo Potengi } \\
\text { Fm. Macaíba }\end{array}$ & $\begin{array}{l}\text { laterização (biostásica) } \\
\text { siderolítica (resist.-tect.-clim.) }\end{array}$ \\
\hline \multirow{3}{*}{$\begin{array}{l}\text { Plioceno } \\
\text { Mioceno } \\
\text { Oligoceno }\end{array}$} & $\underset{5}{\infty}$ & $\begin{array}{l}\text { intemperismo Riacho Morno } \\
\text { Fm. Guararapes }\end{array}$ & $\begin{array}{l}\text { laterizaçào (biostásica) } \\
\text { siderolítica (resist.-clim.-tect.) }\end{array}$ \\
\hline & 总 & $\begin{array}{l}\text { intemperismo laterítico } \\
\text { Fm. Serra do Martins }\end{array}$ & $\begin{array}{l}\text { laterização (biostásica) } \\
\text { siderolítica (resist.-tect.-clim.) }\end{array}$ \\
\hline & & $\begin{array}{l}\text { intemperismo caulínico } \\
\text { embasamento cristalino }\end{array}$ & laterização (biostásica) \\
\hline
\end{tabular}

A origem desses sedimentos também fica bem explicada. Durante as épocas de relativa tranqüilidade tectônica e estabilidade climática, formaram-se solos lateríticos espessos. Três fases de ruptura de equilíbrio causaram a remoção dessas capas de intemperismo e a erosão das rochas subjacentes, redepositando-se o material como os sedimentos das três formações - Serra do Martins, Guararapes e Macaíba.

\section{BIBLIOGRAFIA}

ALMEI1)A. F.F. M. dr - 1969 - Diferenciação tectônica da plataforma brasilcina. Soc. Brats. Geol., Anais XXlli Comer. Salvador (BA). pp. 29446

ANDRADL: G. () de - 19:5 - Itamaracá. Contribuiçâo para o estudo geomorlológico da costa pernambucana. Imprensa Oficial, Recife, 84 $\mathrm{pp}$.

ASSIS, A. D. - I967 - Solânea, nova formação sedimentar do brejo paraibano. 3. Simp. Geol. Nordeste (João Pessoa). resum. comun. (mimeografado)

BIGARLLLLA, J.J, c ABSÁBER, A.N. - 1964-Paläogeographische und palaoklimatische Aspekte des Känowikums in Südbrasilien. Zeitschr. Gomorph., NF 8: 2866-31?2

BIGARLAIA. J. J. c AVIDRADE, G. O. de - 1964 - Considerações sobre a estratigratha, do sedimcntos cenozóicos cm Pernambuco (grupo Barreiras). Univ. Recife, Arq. Insc. Giên. 'Terra, 2: $2-14$

BRANNER, J. C. - 1902 - Geology of the northmeast coast of Brazil. Bull. Geol. Soc. America, 13: $41-98$

BÜDEL, J. - 1953 - Die "periglazial"-morphologischen Wirkungen des Eiszcitklimas aul der ganzen Erde. Erdkunde, 7: 249m266. Bonn (Alemanha)

BULL, W. B. - 1963 - Alluvial fan-deposits in western Fresno Country, California. Journ. Geol., 71: $243-251$

CAMPOS e SILVA, A. - 1965 - O grupo Barreiras na região de Natal. Univ. Fed. Rio Grande do Norte, Inst. Antropol., relat. comun., Geol. 1, 4. pp.

CAMPOS e SILVA, A. - 1968 - O grupo Barreiras e unidades correlatas no Rio Grande do Norte. 4. ${ }^{\circ}$ Simp. Geol. Nordeste (Recife), resum. comun., pp. 21-22

CAMPOS e SILVA, A. - 1969 - Contribuição ao estudo do grupo Barreiras no Rio Grande do Norte. Univ. Fed. Rio Grande do Norte, Arq. Inst. Antropol., publ. s/n, 14. pp. 
COLEMAN, J. e GAGLIANO, S. M. - 1965 - Sedimentary structures: Mississipi deltaic plain. Em: MIDDLETON, G. V. - Primary sedimentary structures and their hydrodynamic interpretation: A Symposium. Soc. Econ. Paleont. Min., Spec. Publ. 12: 133-148

COUTINHO, MARIA G. N. - 1966 - O grupo Barreiras nos Montes Guararapes (Recife). Relat. Iniciação Cient. CNPq (manuscrito)

ERHART, H. - 1956 - La genèse des sols en tant que phénomène géologique. Paris, Masson, $83 \mathrm{pp}$.

FLEURY, E. - 1909 - Le sidérolitique suisse. Contribution à la connaissance des phénomènes d'altération superficielle des sédiments. Mém. Soc. Fribourgeoise Sci. Nat,, 6: $260 \mathrm{pp}$.

FRIEDMAN, G. M. - 1958 - Determination of sieve-size distribution from thin-section data for sedimentary petrological studies. Journ. Geol., 66: 394-416

JENKINS, O. P. - 1913 - Geology of the region about Natal, Rio Grande do Norte. Proc. Amer. Philos. Soc., 52: 431-466

KEGEL, W. - 1957 - Contribuição ao estudo da bacia costcira do Rio Grande do Norte. D.N.P.M., Div. Geol. Min., Bol. 170, 52 pp.

KING, L. C. - 1956 - A geomorfologia do Brasil Oriental. Rev. Bras. Geogr., 18 (2): 147-265

LINS, R. (i. e ANDR.Al)E, G. O. de - 1960 - Os rios da carnaúba; I - O rio Mossori (Apodi). Publ. Inst. Joaquim Nabuco Pesq. Sociais: 148 pp. Recife

MABESOONE, J. M. - 1966 - Relief of northeastern Brazil and its correlated sediments. Zeitschr. Geomorph., NF 10: 419-453

MABESOONE, J. M. - 1967 - Sedimentologia da faixa costeira Recife - João Pessoa. Bol. Soc. Bras. Geol., 16 (l): 57.72

MABESOONE, J. M. - 1968a - Sedimentologia. Recife, Univ. Fed. Pernambuco, Imprensa Univ., $478 \mathrm{pp}$.

MABESOONE, J. M. - 1968b - Pezaj mineraloj en la sedimentoj de la grupo Barreiras en Pernambuko (Brazilo). Geol. Internacia, 1: 37-43. Praha

MATOSO, S. Q. e ROBERTSON, F. S. - 1959 - Uso geológico do termo "Barreiras", Bol. Técn. Petrobrás, 2 (3): 37-43

MILLO'T, G. - 1967 - Signification des études récentes sur les roches argileuses dans l'interprétation des faciès sédimentaires (y compris les séries rouges). Sedimentology, 8: 259-280)

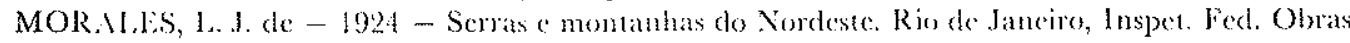
contra Seccas, sér. I. D, publ. 58 (2 vol.), 122 e 120 pp.

OLIVEIRA, A. I. e LEONARDOS, O. H. - 1943 - Geologia do Brasil (2. ${ }^{a}$ ed.). Rio de Janeiro, Min. Agricultura, Serv. Inform., $813 \mathrm{pp}$.

OLIVEIRA, P. E. e RAMOS, J. R.A. - 1956 - Geologia das quadrículas de Recife e Pontas de Pedra. D.N.P.M., Div. Geol. Min., Bol. 151: 60 pp.

RAO, A. B., ASSIS, A. D. e SILVA, J. C. - 1962 - DTA das argilas da formação Barreiras; I - Seção Goiana-Recife; II - Seção Recife-Moreno. Univ. Recife, Arq. Geol., 2: 37-57; 3: 43-53

SUDENE-ASMIG - 1967 - Estudo geral de base do vale do Jaguaribe; 7 - Hidrogeologia. Recife, G.V.J., 245 pp. (esp. pp. 173-178) 